ВІСНИК

ОДЕСЬКОГО НАЦІОНАЛЬНОГО

МОРСЬКОГО УНІВЕРСИТЕТУ

№ 3 (60), 2019
HERALD

OF THE ODESSA NATIONAL

MARITIME UNIVERSITY

№ 3 (60), 2019

УДК 621.74-222.004

DOI 10.33082/2226-1893-2019-3-86-92

\title{
МОНИТОРИНГ ТЕХНИЧЕСКОГО СОСТОЯНИЯ СУДОВЫХ МАЛООБОРОТНЫХ ДИЗЕЛЕЙ
}

\author{
В.А. Кузнецов \\ аспирант \\ кафедры «Техническое обеспечение и ремонт судов» \\ Одесский национальный морской университет, Одесса, Украина
}

Аннотация. В процессе работы были определены требования, предъявляемые к деталям ЦПГ малооборотных дизелей. Особо важную роль в длительной и надежной эксплуатачии дизелей играет мониторинг и диагностирование узлов и механизмов для качественной оценки их технического состояния. Мониторинг является частью технического обслуживания любых энергетических установок независимо от типа судна, а также различных устройств и систем в целом. Цель ее заключается 6 получении своевременной информации о техническом состоянии отдельных деталей, узлов, механизмов двигателя в иелом на основе проведения измерений и анализа результатов измерений различных параметров. Как бы долго малооборотные двигатели не эксплуатировались со временем их приходиться ремонтировать, поэтому компаниями занимающимися изготовлениями судовых дизелей предоставляться технические средства и необходимый качественно-подготовленный персонал способный диагностировать поломанный узел механизма, произвести его дефектацию, определить объём, сроки выполнения и стоимость ремонта. Надежность работы двигателя необходимо поддерживать постоянно на всех этих этапах т.к. от качества выполненных по ремонту работ зависит безопасность мореплавания судна, что в свою очередь контролируется международной морской организачией (ИМО).

Ключевые слова: судовой дизель, отказ, мониторинг, техническое состояние, судовая надежность.

УДК 621.64:351.745

DOI 10.33082/2226-1893-3-2019-3-86-92

\section{МОНІТОРІНГ ТЕХНІЧНОГО СТАНУ СУДНОВИХ МАЛООБЕРТОВІХ ДИЗЕЛІВ}

\author{
B.А. Кузнєцов \\ аспірант
}

кафедри «Технічного забезпечення та ремонту суден»

Одеський наиіональний морський університет, Одеса, Украӥна

(C) Кузнецов В.А., 2019 
ВІСНИК

ОДЕСЬКОГО НАЦІОНАЛЬНОГО

МОРСЬКОГО УНІВЕРСИТЕТУ
HERALD

OF THE ODESSA NATIONAL

MARITIME UNIVERSITY № 3 (60), 2019

У прочесі роботи були визначені вимоги, щуо пред'являються до деталей ЦПГ малообертових двигунів. Особливо важливу роль в тривалій і надійної експлуатації дизелів грає моніторинг, та діагностування вузлів $i$ механізмів. Моніторинг є частиною технічного обслуговування будьяких енергетичних установок незалежно від типу судна, а також різних пристроїв $і$ систем в иілому. Мета ї̈ полягає в отриманні своєчасної інформацї про технічний стан окремих деталей, вузлів, механізмів двигуна в цілому. Як би довго малообертові двигуни не експлуатувалися $з$ часом їх доводиться ремонтувати, тому компанії які займаються виготовленням суднових дизелів надають технічні засоби та необхідний якісно-підготовлений персонал здатний діагностувати поламаний вузол механізму, провести його дефектацию, визначити обсяг, терміни виконання $і$ вартість ремонту. Надійність роботи двигуна необхідно підтримувати постійно на всіх цих етапах тому як від якості виконаних по ремонту робіт залежить безпека мореплавання судна, щуо в свою чергу контролюється міжнародною морською організацією (IMO).

Ключові слова: судновий дизель, відмова, моніторинг, технічний стан, суднова надійність.

UDC 621.64:351.745

DOI 10.33082/2226-1893-2019-3-86-92

\title{
MONITORING THE TECHNICAL CONDITION OF SHIP'S LOW-TURNING DIESELS
}

\author{
V.A. Kuznetsov \\ graduate student \\ Department «Technical support and repair of ships» \\ Odessa National Maritime University
}

\begin{abstract}
In the process of job determined the requirements for the details of the CPG of low-speed diesel engines. A particularly important role in the long and reliable operation of diesel engines is played by monitoring and diagnosis of components and mechanisms for a qualitative assessment of their technical condition. Monitoring is part of the maintenance of any power plants, regardless of the type of vessel, as well as various devices and systems in general. Its purpose is to obtain timely information on the technical condition of individual parts, assemblies, engine mechanisms as a whole based on measurements and analysis of the measurement results of various parameters. No matter how long low-speed engines are used, they have to be repaired over time, therefore, companies engaged in the manufacture of marine diesel engines are provided with technical equipment and the necessary qualitytrained personnel capable of diagnosing a broken part of the mechanism, diagnosing it, determining the volume, timing and cost of repairs. The reliability of the engine must be maintained constantly at all these stages since
\end{abstract}


the safety of the navigation of the vessel depends on the quality of the repair work, which in turn is controlled by the international maritime organization (IMO). reliability.

Keywords: marine diesel, failure, monitoring, technical condition, ship

При эксплуатации морских судов прежде всего предусмотрено усиление мер по безопасности мореплавания. Этим постоянно занимается международная морская организация (ИМО). Работа проводится в различных направлениях. Одним из приоритетных является международный кодекс по управлению безопасностью (МКУБ).

Важным объектом при эксплуатации судна с точки зрения безопасности плавания является эксплуатационная надежность судовых дизелей. Техническое состояние главной силовой установки (на современных морских судах это малооборотные двигатели) зависит от правильного решения вопросов выбора конструкций, производства и эксплуатации. Надежность работы двигателя необходимо поддерживать постоянно на всех этих этапах.

Как бы долго двигатели не эксплуатировались, их приходится ремонтировать. Причиной выхода двигателя из эксплуатации являются отказы отдельных деталей и узлов, которые теряют с течением времени физико-механические свойства. Поэтому, прежде всего, необходимо провести анализ причин выхода деталей и узлов из эксплуатации. Это очень важный и ответственный этап работы. Затем производится дефектация, после которой устанавливается последовательность, объём, сроки выполнения и стоимость ремонта. При этом важно проводить мониторинг технического состояния малооборотный двигателей.

Необходимо рассматривать системный подход к мониторингу технического состояния малооборотный двигателей.

Эксплуатационная надежность малооборотный двигателей в значительной степени определяется отказами деталей ЦПГ. Это поршни, цилиндровые втулки, крышки, клапаны, детали топливной аппаратуры. Этот узел работает в тяжёлых условиях при высокой температуре, давлении, коррозионной среде. Поэтому при дефектации и ремонте на этот узел необходимо обратить особое внимание.

Важным мероприятием при исследовании эксплуатационной надежности малооборотных дизелей является контроль и анализ причин появления характерных дефектов, и их влияние на условия эксплуатации. Основными причинами появления отказов и повреждений деталей являются высокие нагрузки, повышенные температуры, агрессивная среда и др.

Обзор характерных дефектов, причины их возникновения, средства обнаружения, дефекты, способы их устранения и контроля показаны в таблице 1 . 
Дефекты деталей, причины возникновения,

Таблииа 1

способы обнаружения, способы устранения, методы контроля

\begin{tabular}{|c|c|c|c|c|c|}
\hline $\begin{array}{l}\text { Дефекты } \\
\text { деталей }\end{array}$ & Износ & Трещины & Коррозия & Эрозия & $\begin{array}{c}\text { Уста- } \\
\text { лость } \\
\text { металла } \\
\end{array}$ \\
\hline $\begin{array}{l}\text { Причины } \\
\text { вызываю- } \\
\text { щие дефек- } \\
\text { ты деталей }\end{array}$ & $\begin{array}{l}\text { Трение, } \\
\text { действие } \\
\text { высоких } \\
\text { темпера- } \\
\text { тур и } \\
\text { нагрузок. }\end{array}$ & $\begin{array}{l}\text { Температур- } \\
\text { ные, конструк- } \\
\text { торско техно- } \\
\text { логические } \\
\text { недостатки, } \\
\text { нарушение } \\
\text { правил техни- } \\
\text { ческой эксплу- } \\
\text { атации. }\end{array}$ & $\begin{array}{l}\text { Влага, } \\
\text { агрессив- } \\
\text { ная сре- } \\
\text { да. }\end{array}$ & $\begin{array}{l}\text { Кавитация, } \\
\text { поток газа и } \\
\text { жидкости. }\end{array}$ & $\begin{array}{l}\text { Знакопе- } \\
\text { ременные, } \\
\text { длитель- } \\
\text { ные на- } \\
\text { грузки. }\end{array}$ \\
\hline $\begin{array}{l}\text { Средства } \\
\text { обнаруже- } \\
\text { ния дефек- } \\
\text { тов }\end{array}$ & $\begin{array}{l}\text { Измери- } \\
\text { тельный } \\
\text { инстру- } \\
\text { мент. } \\
\end{array}$ & $\begin{array}{l}\text { Дефектоскопы, } \\
\text { магнитный } \\
\text { метод. }\end{array}$ & $\begin{array}{l}\text { Визу- } \\
\text { альный } \\
\text { осмотр, } \\
\text { лупы. }\end{array}$ & $\begin{array}{l}\text { Визуальный } \\
\text { осмотр. }\end{array}$ & $\begin{array}{l}\text { Ультра- } \\
\text { звук, гам- } \\
\text { маграфи- } \\
\text { рование. }\end{array}$ \\
\hline $\begin{array}{l}\text { Способы } \\
\text { устранения } \\
\text { дефектов }\end{array}$ & $\begin{array}{l}\text { Наплавка, } \\
\text { механиче- } \\
\text { ская обра- } \\
\text { ботка, } \\
\text { замена. }\end{array}$ & $\begin{array}{l}\text { Заварка, заме- } \\
\text { на, подкрепле- } \\
\text { ние, изменение } \\
\text { конструкции. }\end{array}$ & $\begin{array}{l}\text { Механи- } \\
\text { ческая } \\
\text { обработ- } \\
\text { ка, на- } \\
\text { плавка и } \\
\text { окраска. }\end{array}$ & $\begin{array}{l}\text { Механиче- } \\
\text { ская обра- } \\
\text { ботка, свар- } \\
\text { ка, наплавка, } \\
\text { окраска }\end{array}$ & $\begin{array}{l}\text { Механиче- } \\
\text { ская обра- } \\
\text { ботка. }\end{array}$ \\
\hline $\begin{array}{l}\text { Методы } \\
\text { контроля }\end{array}$ & $\begin{array}{l}\text { Магнит- } \\
\text { ная, цвет- } \\
\text { ная дефек- } \\
\text { тоскопия. }\end{array}$ & $\begin{array}{l}\text { Магнитный } \\
\text { метод, гамма- } \\
\text { метод, ультра- } \\
\text { звук. }\end{array}$ & $\begin{array}{l}\text { Визу- } \\
\text { альный } \\
\text { осмотр, } \\
\text { измере- } \\
\text { ния. }\end{array}$ & $\begin{array}{l}\text { Визуальный } \\
\text { осмотр }\end{array}$ & $\begin{array}{l}\text { Гаммагра- } \\
\text { фирова- } \\
\text { ние, ульт- } \\
\text { развук. }\end{array}$ \\
\hline
\end{tabular}

«Удельный вес» отказов и повреждений деталей двигателя различен, так на долю поршней, крышек, втулок, т.е. деталей ЦПК приходится около $40 \%$, на детали топливной аппаратуры около $20 \%$, остальные - на подшипники и механизмы обслуживающие главный двигатель [1].

Малооборотные двигатели обладают большими ресурсам экономичностью надежной конструкцией и высокой агрегатной мощностью Для обеспечения эксплуатационной надежности главных энергетических установок необходимо проводить их техническое обслуживание. При этом применяются различные методы и способы их проведения. Так, по данным фирме Вяртсила техническое обслуживание до отказа занимает около $55 \%$, по плану около $31 \%$, по состоянию около $12 \%$, другие около $2 \%$ [2]. 
Каждый из этих методов технического обслуживания имеет свои преимущества и недостатки. Его выбор решается в судоходной компании, при этом необходимо проводить мониторинг технического состояния судовых дизелей

Мониторинг это непрерывный процесс сбора и анализа информации о значении диагностируемых параметров состояния объекта. Контроль мониторинга может осуществляться в реальном времени или дистанционно.

Мониторинг параметров судовых дизелей является важной предпосылкой безопасности плавания морских судов, обеспечивая при этом надежную работу главной энергетической установки [3].

Информация полученная от электронных систем управления двигателем обрабатывается центральным компьютером управления либо компьютером машинного отделения. Мониторинг производится по многим параметрам двигателя. Ниже приводится перечень ряда параметров малооборотных двигателей при проведениии мониторинга расхода топлива. Давление впрыска, частота вращения коленвала, характеристика рабочего процесса двигателя в период эксплуатации, скорость нарастания давления, температура газов в по цилиндрам, расход топлива, расход масла, учет вибрации в крышках цилиндра и коленчатом валу, давление наддува в турбонагнетателе, а так же дымность выпускных газов.

Современные измерительные системы позволяют осуществить мониторинг технического состояния двигателя с высокой степенью надежности.

Для мониторинга технического состояния судовых дизелей при-меняется современные компьютерные системы контроля измеряемых параметров. Так для контроля параметров рабочего процесса судовых дизелей применяется система «DEPAS». Она позволяет увеличить срок службы двигателей и сократить затраты на его обслуживание.

«DEPAS» - это Diesel Engine performance analysing System: Данная система разработана в лаборатории «Мониторинг СДВС» в Одесском национальном морском университете.

Фирмой «Wartsila» предложена программа управления системой технического обслуживания малооборотных двигателей «WECS» (Wartsila Engine Control System). Данная система дает возможность предупредить поломки, вырабатывает рекомендации по внесению изменений в организацию технического обслуживания этих двигателей.

Полученные данные измерений сопоставляются с эталонными и определяются значения отклонений. По этим значениям оценивается состояние двигателя и обслуживающих его систем.

Аналогичная компьютерная система технического обслуживания предлагается фирмой MAN \& BW. 
Центром технического обслуживания является судоходная компания. В офис компании ежемесячно направляется отчёты отражающие состояние исследуемых объектов на текущий момент и прогноз на будущее.

Многие фирмы оборудуют выпускаемые ими двигатели микропроцессорами и измерительными приборами. На них возлагается задача мониторинга наиболее важных параметров, сигнализации о их выходе за установленные пределы и отслеживание развития параметров во времени. Работа осуществляется в автоматическом режиме.

\section{Выводы}

1. Опыт эксплуатации мало оборотных двигателей свидетельствует о том, что для надежной их работы прежде всего необходимо обратить внимание на контроль параметров деталей ЦПГ.

2. Приведен обзор характерных дефектов деталей ЦПГ двигателей, причины их появления, средства обнаружения способы их устранения и контроля.

3. Указано на важность проведения мониторинга технического состояния малооборотных двигателей с целью повышения их эксплуатационной надежности.

\section{СПИСОК ЛІТЕРАТУРИ}

1. Сторожев В.П. Причины и закономерности постепенных отказов основных триботехнических объектов энергетической системы судна и повышения их ресурса. Одесса, 2001. $341 \mathrm{c}$.

2. Возницкий И.В. Двигатели $M A H B \& W$ модельного ряда $M C$ 50-98. Конструкция, эксплуатация, техническое обслуживание. М.: МОРКНИГА, 2008. $264 \mathrm{c.}$

3. Богач В.Т., Давиденко Ю.М. Характеристики прочесу мащення ииліндро-поршневої групи двигунів RTA. Cуднові енергетичні установки: науково-технічний збірник. Вип. 38. Oдеса: НУ «OMA», 2019. 312 c.

\section{REFERENCES}

1. Storogev V.P. (2000) Prichiny i zakonomernosti postepennyh otkazov osnovnyh tribotehnicheskih obektov energeticheskoj sistemy sudna i povyshenie ih resursa [Reasons and patterns of gradual failures of the main tribotechnical facilities of the ship's energy system and increase of their resource]. Odessa: Feniks, pp. 341 (in Ukraine). 
ВІСНИК

ОДЕСЬКОГО НАЦІОНАЛЬНОГО

МОРСЬКОГО УНІВЕРСИТЕТУ

№ 3 (60), 2019
HERALD

OF THE ODESSA NATIONAL

MARITIME UNIVERSITY

№ 3 (60), 2019

2. Voznitskiy I.V. (2008) Dvigateli MAN B\&W modelnogo ryada MS 50-98. Konstrukciya, ekspluataciya, tehnicheskoe obsluzhivanie [Engines MAN B\&W model range MS 50-98. Design, operation, maintenance]. Moskow: Morkniga, pp. 264 (in Russia).

3. Bogach V.N., Davidenko Y.M. (2019) Harakteristiki procesu mashennya cilindro - porshnevoyi grupi dviguniv RTA. Sudnovi energetichni ustanovki: naukovo tehnichnij zbirnik. [Characteristics of the lubrication process of the cylinder - piston group of RTA engines. Ship Power Plants: Scientific and Technical Collection vol 38]. Odessa: $N U$ «OMA», pp. 312 (in Ukraine).

Стаття надійшла до редакиії 28.10.2019 